\title{
Procedural Predictors and Outcomes of Percutaneous Secundum Atrial Septal Defect Closure in Children Aged $<6$ Years
}

\author{
Seul Gi Cha, MD; Mi Jin Kim, MD; Jae Suk Baek, MD, PhD; \\ Jeong Jin $\mathrm{Yu}, \mathrm{MD}, \mathrm{PhD}$; Young-Hwue Kim, MD, PhD
}

\begin{abstract}
Background: Percutaneous atrial septal defect (ASD) closure is the treatment of choice for patients with a suitable ASD anatomy; however, the procedural characteristics and outcomes in children aged $<6$ years are unclear. The feasibility and safety of percutaneous ASD closure in children aged $<6$ years was evaluated and the predictors of procedural failure and challenging cases were identified.

Methods and Results: Patients from a single center between 2006 and $2018(\mathrm{n}=407)$ were retrospectively evaluated. There were $265(65.1 \%)$ female patients. The median age at the time of the procedure and ASD size were $3.4(0.9-5.9)$ years and 13.3 (3.8-27.0) $\mathrm{mm}$, respectively. Medical records and echocardiographic images were analyzed. A challenging case was indicated by the use of non-conventional techniques. The procedure was completed in 399 patients (98.0\%). Post-procedural acute complications occurred in 5 patients, including 1 with device embolization. Two patients underwent surgical device removal. During the follow up (30.3 [3.6-140.8] months), aggravated mitral regurgitation occurred in 5 patients. A multivariate logistic regression revealed large-sized ASD as a predictor of procedural failure (odds ratio $=1.828,95 \%$ confidence interval: $1.139-2.934, P=0.012$ ) and challenging cases (odds ratio=1.371, 95\% confidence interval: $1.180-1.593, \mathrm{P}<0.001$ ).
\end{abstract}

Conclusions: Percutaneous ASD closure is feasible and safe in children aged $<6$ years; however, patients with large-sized ASD are at high risk of procedural failure and becoming a challenging case.

Key Words: Congenital heart defects; Pediatric intervention; Preschool children; Septal occluder

$\mathbf{S}$ ecundum atrial septal defect (ASD) is one of the most common congenital heart defects (CHD) with a mean incidence of $947 / 1,000,000$ live births. ${ }^{1}$ American Heart Association Guidelines recommend an elective closure in asymptomatic patients aged between 2 and 5 years with a large left-to-right shunt. ${ }^{2}$ In 1976 , King et al reported the first case of percutaneous ASD closure. ${ }^{3}$ Since early 2000, percutaneous ASD closure is the treatment of choice for patients with a suitable ASD anatomy ${ }^{4,5}$ after the creation of the Amplatzer ${ }^{\circledR}$ Septal Occluder. ${ }^{6}$ In the early era of percutaneous ASD closure, defects with rim deficiencies were thought to be associated with device deployment failure. ${ }^{7,8}$ However, with the recent advances in novel devices ${ }^{9,10}$ and techniques for device deployment, ${ }^{11-13}$ the clinical field of percutaneous ASD closure has been widened. Nowadays, percutaneous ASD closure is attempted in patients with large ASDs and some deficient rims; ${ }^{\mathbf{1 4}, 15}$ however, cases that require novel techniques (so-called non-conventional methods) remain challenging. Although a recent large nationwide study of 1,326 children and adolescents from France (the median age was 9 years) demonstrated the safety and favorable outcomes of percutaneous ASD closure in children and adolescents, ${ }^{14}$ percutaneous ASD closure in children aged $<6$ years has not been adequately investigated. Therefore, this study aimed to prove the feasibility and safety of percutaneous ASD closure in young children (aged $<6$ years) and identify predictors for procedural failure and challenging cases.

\section{Methods}

\section{Study Design}

This retrospective study was conducted at a single tertiary congenital heart disease center. All children aged $<6$ years who were diagnosed with secundum ASD and underwent percutaneous ASD closure from 2006 to 2018 were enrolled in this study. We targeted the age group in the guidelines (2-5 years), therefore, the patients were aged $<6$ years. Patients with complex CHD were excluded. Patients' medical records were reviewed to acquire their demographic and

Received October 2, 2020; revised manuscript received February 1, 2021; accepted February 6, 2021; J-STAGE Advance Publication released online April 21, 2021 Time for primary review: 23 days

Division of Pediatric Cardiology, Asan Medical Center, University of Ulsan College of Medicine, Seoul, Korea

Mailing address: Young-Hwue Kim, MD, PhD, Division of Pediatric Cardiology, Asan Medical Center, University of Ulsan College of Medicine, 88, Olympic-Ro, Songpa-Gu, Seoul 05505, Korea. E-mail: yhkim@amc.seoul.kr

All rights are reserved to the Japanese Circulation Society. For permissions, please e-mail: cj@j-circ.or.jp

ISSN-1346-9843 
clinical information. All pre-, intra-, and post-procedural echocardiographic images were retrospectively reviewed and analyzed using TomTec software (Image Arena VA version 4.6; TomTec Imaging Systems, Unterschleissheim, Germany). The present study was approved by the institutional review board of Asan Medical Center (Approval number 2020-0339); this study was exempted from obtaining patients' informed consent because of its retrospective nature.

\section{Percutaneous ASD Closure and Procedural Data}

We followed the American Heart Association Guidelines ${ }^{2}$ for the ASD closure. We considered elective ASD closure in asymptomatic patients between the age of 2 and 5 years with a confirmed large left-to-right shunt (right atrial and ventricular enlargement and/or calculated $\mathrm{Qp} / \mathrm{Qs}$ over 1.5). In patients aged $>3$ years whose ASD anatomy was proper for percutaneous closure, we performed the intervention first. If the patient was symptomatic, we occasionally performed percutaneous ASD closure before the age of 3 years.

Pre-interventional trans-thoracic echocardiography (TTE) was performed on all candidates for percutaneous closure. In our center, rims around the defect were measured in 3 planes of pre-procedural TTE. Superior vena cava (SVC) and inferior vena cava (IVC) rims were measured in the subxiphoidal view (either short-axis or bicaval view). Posteriorsuperior (PS) and mitral valve (MV) rims were measured in the 4-chamber view, and retro-aortic and posterior-inferior (PI) rims were measured in either the parasternal short axis or sub-xiphoidal right anterior-oblique view. ${ }^{16}$ We chose clear and definite images to measure retro-aortic and PI rims. We considered 3 anatomical criteria for transcatheter ASD closure: (1) sufficient MV rim $>5 \mathrm{~mm}$; (2) no multiple rim deficiency based on measurements in 3 planes (except the retro-aortic rim), although the cut-off was not $5 \mathrm{~mm}$; and (3) no absent rim (except retro-aortic rim), which was considered a sinus venosus defect. The single cut-off value of SVC, PS, and PI rims were lower (1-3 mm) than that of the MV rim, unless there was a multiple rim deficiency. We considered that the IVC rim was also important for a safe device deployment; therefore, the cut-off value of the IVC rim was stricter than that of the SVC, PS, and PI rims $(3-5 \mathrm{~mm})$. For patients who were not eligible for transcatheter closure, we considered surgical ASD closure. In our center, we predominantly perform surgical ASD closure in cases of small MV or IVC rims $(<4 \mathrm{~mm}$ for MV rim and $2 \mathrm{~mm}$ for IVC rim).

If the rim measurement was not recorded, we measured the rim retrospectively with TTE or trans-esophageal echocardiography (TEE). In this study, rim deficiency was defined as a measurement of $<5 \mathrm{~mm} .{ }^{17}$

All procedures were conducted under general anesthesia and via the femoral vein; they were all guided using TEE and anteroposterior plain fluoroscopy. ASD size was defined as the maximum diameter of the defect or the measurement of the sizing balloon in TEE for patients in whom the sizing balloon was used. ASD size was used in determining the device size. We only performed balloon sizing in patients with a floppy rim, or large or multiple defects. We determined the device size to be $1-2 \mathrm{~mm}$ more than the maximum defect size in TEE. In cases of balloon sizing, we determined the device size to be $0-1 \mathrm{~mm}$ smaller than the measured balloon diameter in TEE. During the procedure, we used the conventional method first. If we failed to deploy the device using the conventional method, other methods were used. The detailed process of percutaneous ASD closure was described in previous studies on percutaneous ASD closure conducted at our center. ${ }^{16}$

Our center used several types of devices as follows: Amplatzer ${ }^{\circledR}$ Septal Occluder, Amplatzer ${ }^{\circledR}$ Cribriform Septal Occluder, Amplatzer ${ }^{\circledR}$ PFO Occluder (Abbott Medical, Abbott Park, IL, USA), Cocoon ${ }^{\circledR}$ Septal Occluder (Vascular Innovations Co., Nonthaburi, Thailand), Occlutech ${ }^{\circledR}$ Figulla Flex II (Occlutech International AB, Helsingborg, Sweden), and Gore ${ }^{\circledR}$ Cardioform Septal Occluder (WL Gore \& Associates, Flagstaff, AZ, USA).

The conventional method was defined as the deployment of the device across the defect as described in previous literature. ${ }^{4,18} \mathrm{We}$ considered the balloon-assisted technique ${ }^{12}$ and slide-out or pulmonary vein technique ${ }^{11,16}$ to be nonconventional methods, indicating challenging cases.

Completion of percutaneous ASD closure was defined as the appropriate deployment and release of the ASD device without intra-procedural complications. Procedural failure was defined as device deployment failure or the occurrence of intra-procedural complications after device deployment resulting in the withdrawal of the device.

\section{Peri-Procedural and Follow-up Data}

Post-procedural acute complication was defined as the occurrence of complications during admission. Patients who had one or more post-discharge echocardiograms were included in the follow-up analysis. The degree of mitral regurgitation (MR) was evaluated numerically from grade 0 (none) to 4 (severe). The aggravation of MR was defined as an increase of one or more grades between pre- and postinterventional echocardiography.

\section{Statistical Analysis}

Demographic data were reported as median values with minimum and maximum ranges; statistical data were reported as means \pm standard deviations. We used a logistic regression model to identify predictors of procedural failure and nonconventional methods. In the logistic regression model, the univariate analysis identified variables with $\mathrm{P}<0.10$ that were then entered into a multivariate analysis in a stepwise fashion. Odds ratios and 95\% confidence intervals (CI) were presented for the logistic regression model. The types of device could affect the analysis, thus we performed a logistic regression analysis only for patients with a single Amplatzer ${ }^{\circledR}$ Septal Occluder (including failed cases). The number of patients with this device was large enough for the analysis; however, the number of patients with the other devices was too low. In the logistic regression analysis, we wanted to perform a rim evaluation for procedure failure and using a non-conventional method in the pre-procedural period; thus, we used the pre-procedural TTE data for the rim evaluation. We set a combination of a deficiency of 2 rims as independent factors, including retroaortic-PI rims, SVC-PS rims (superior rims), PS-PI rims (posterior rims), SVC-PI rims, and IVC-retroaortic rims deficiency. There was no patient with a combination deficiency of IVC and MV rims. Therefore, we did not choose IVC-MV rim deficiency as an independent factor. We selected the absolute values of ASD size and rim measurement as independent factors, not the indexed values, because the absolute values had a bigger impact on the study analysis than the indexed values. We wanted to avoid multicollinearity; thus, we only used the absolute values of ASD size and rim measurement as covariates in the logistic regression model. The receiver 


\begin{tabular}{|c|c|}
\hline & $\begin{array}{c}\text { Number }(\%) \text { or } \\
\text { median } \\
\text { (minimum- } \\
\text { maximum value) }\end{array}$ \\
\hline Number of patients & $(n=407)$ \\
\hline Female & $265(65.1)$ \\
\hline Combined CHD & $47(11.5)$ \\
\hline MVP (including mild degree) & 13 \\
\hline $\begin{array}{l}\text { Valvar pulmonary stenosis (s/p } \\
\text { pulmonary BVP 4) }\end{array}$ & 12 \\
\hline $\begin{array}{l}\text { PDA (silent/simultaneous percutaneous } \\
\text { PDA closure) }\end{array}$ & $7(4 / 3)$ \\
\hline VSD & 4 \\
\hline Peripheral pulmonary stenosis & 3 \\
\hline Others & 8 \\
\hline Syndrome or other systemic anomalies & $19(4.7)$ \\
\hline Down & 6 \\
\hline Microdeletion 22q11 & 3 \\
\hline Others & 10 \\
\hline \multicolumn{2}{|l|}{ At ASD device closure } \\
\hline Age (years) & $3.4(0.9-5.9)$ \\
\hline Height $(\mathrm{cm})$ & $97.0(71.0-120.0)$ \\
\hline Weight (kg) & $14.6(8.4-24.0)$ \\
\hline $\mathrm{BSA}\left(\mathrm{m}^{2}\right)$ & $0.62(0.31-0.89)$ \\
\hline Characteristics of ASDs & $(n=407)$ \\
\hline \multicolumn{2}{|l|}{ Number of ASDs } \\
\hline One & $348(85.5)$ \\
\hline Multiple & $59(14.5)$ \\
\hline Atrial Septal Malalignment & $15(3.7)$ \\
\hline Maximum measurement of ASD in TEE $(\mathrm{mm})$ & $13.0(3.8-25.5)$ \\
\hline $\begin{array}{l}\text { Final ASD size on TEE (with or without } \\
\text { sizing balloon) }(\mathrm{mm})\end{array}$ & $13.3(3.8-27.0)$ \\
\hline \multicolumn{2}{|l|}{$\begin{array}{l}\text { Rims }(\mathrm{mm}) \text { (deficient cases/total cases } \\
\text { with available data) }\end{array}$} \\
\hline SVC rim $(\mathrm{mm})(26 / 387)$ & $9.9(2.3-27.6)$ \\
\hline IVC rim (mm) (11/387) & $11.2(1.3-27.4)$ \\
\hline retroAo rim $(\mathrm{mm})(350 / 387)$ & $2.4(0.0-15.0)$ \\
\hline PI rim $(\mathrm{mm})(46 / 385)$ & $7.7(1.2-17.4)$ \\
\hline MV rim $(\mathrm{mm})(5 / 386)$ & $9.2(4.4-21.0)$ \\
\hline PS rim (mm) (38/384) & $8.4(1.5-19.0)$ \\
\hline
\end{tabular}

(Table 1 continued the next column.)

operating characteristic (ROC) curve and area under the ROC curve (AUC) based on the logistic regression model were also presented. We considered $\mathrm{P}$ values $<0.05$ to be statistically significant.

\section{Results}

\section{Clinical Characteristics}

During the study period, 407 patients aged $<6$ years underwent percutaneous ASD closure, and 191 patients aged $<6$ years underwent surgical closure in our center. Thus, 407 patients were included in the study. Of them, $265(65.1 \%)$ were female. Forty-seven patients $(11.5 \%)$ had another congenital heart disease, and MV prolapse was the most common (13 patients) (Table 1). Fifteen patients had mild atrial septal malalignment. At the percutaneous ASD closure attempt, the median age was 3.4 years $(0.9-5.9)$, and the median body weight and body surface area were $14.6 \mathrm{~kg}$

\begin{tabular}{|c|c|}
\hline & $\begin{array}{c}\text { Number }(\%) \text { or } \\
\text { median } \\
\text { (minimum- } \\
\text { maximum value) }\end{array}$ \\
\hline \multicolumn{2}{|l|}{ During procedure } \\
\hline Using sizing balloon & $64(15.7)$ \\
\hline Intervention & $(n=407)$ \\
\hline Failure & $8(2.0)$ \\
\hline Failure of device deployment & 4 \\
\hline $\begin{array}{l}\text { Intra-procedural complication (MV } \\
\text { compression/cAVB) }\end{array}$ & $4(3 / 1)$ \\
\hline Completion & $399(98.0)$ \\
\hline \multicolumn{2}{|l|}{ Methods } \\
\hline Conventional & $343(86.0)$ \\
\hline Other techniques & $56(14.0)$ \\
\hline PV technique & 33 \\
\hline Balloon-assisted technique & 23 \\
\hline \multicolumn{2}{|l|}{ No. of devices } \\
\hline 1 & $393(98.5)$ \\
\hline 2 & $6(1.5)$ \\
\hline Size of devices $(\mathrm{mm})$ & $14.0(3.0-30.0)$ \\
\hline Type of devices (Using single device) & $(\mathrm{n}=401)($ failed in 8$)$ \\
\hline Amplatzer ${ }^{\circledR}$ Septal Occluder & 280 (failed in 5) \\
\hline Amplatzer ${ }^{\circledR}$ Cribriform Septal Occluder & 2 \\
\hline Amplatzer ${ }^{\circledR}$ PFO Occluder & 1 \\
\hline Cocoon $^{\circledR}$ Septal Occluder & 36 \\
\hline Occlutech $^{\circledR}$ Figulla Flex II & 81 (failed in 3) \\
\hline Gore ${ }^{\circledR}$ Cardioform Septal Occluder & 1 \\
\hline Type of devices (Using 2 devices) & $(n=6)$ \\
\hline 2 Amplatzer ${ }^{\circledR}$ Septal Occluder devices & 4 \\
\hline 2 Cocoon $^{\circledR}$ Septal Occluder devices & 1 \\
\hline $\begin{array}{l}\text { Occlutech }^{\circledR} \text { Figulla Flex II+ } \\
\text { Amplatzer }^{\circledR} \text { Septal Occluders }\end{array}$ & 1 \\
\hline
\end{tabular}

ASD, atrial septal defect; BSA, body surface area; BVP, balloon valvuloplasty; CAVB, complete atrioventricular block; $\mathrm{CHD}$, congenital heart defect; IVC, inferior vena cava; MV, mitral valve; MVP, mitral valve prolapse; PDA, patent ductus arteriosus; PI, posterior-inferior; PS, posterior-superior; PV, pulmonary vein retroAo, retro-aortic; s/p, status post; SVC, superior vena cava; TEE, transesophageal echocardiography; VSD, ventricular septal defect.
$(8.4-24.0 \mathrm{~kg})$ and $0.62\left(0.31-0.89 \mathrm{~m}^{2}\right)$, respectively (Table 1). Among 407 enrolled patients, $348(85.5 \%)$ had 1 defect, whereas the remaining $59(14.5 \%)$ had $\geq 2$ defects (Table 2). The median value of the maximum diameter of the defect in TEE was $13.0 \mathrm{~mm}(3.8-25.5 \mathrm{~mm})$, and the median final ASD size on TEE with or without sizing balloon was $13.3 \mathrm{~mm}(3.8-27.0 \mathrm{~mm})$. The median values of each rim are listed in Table 1.

\section{Procedure Data}

During the procedure, balloon sizing was performed in 64 patients $(15.7 \%)$. The procedure was completed with appropriate device deployment and release in 399 patients (98.0\%) (Table 1). Percutaneous ASD closure failed in eight patients $(2.0 \%)$; the causes were device deployment failure (4 patients), MV compression (3 patients), and complete atrioventricular block (1 patient) after device deployment. Among 399 completed procedures, we used non-conven- 


\begin{tabular}{|c|c|}
\hline & $\begin{array}{c}\text { Number }(\%) \text { or } \\
\text { median } \\
\text { (minimum- } \\
\text { maximum value) }\end{array}$ \\
\hline Completion of the procedure & $(n=399)$ \\
\hline $\begin{array}{l}\text { Post-procedural acute complications } \\
\text { (within admission) }\end{array}$ & $5(1.3)$ \\
\hline Device embolization & $1(0.3)$ \\
\hline $\begin{array}{l}\text { Percutaneous removal and re-closure } \\
\text { using larger device }\end{array}$ & 1 \\
\hline PV, SVC, or IVC flow disturbance & $0(0)$ \\
\hline Aortic erosion & $0(0)$ \\
\hline $\begin{array}{l}\text { MV problem (LA disc touching MV, not } \\
\text { compression) }\end{array}$ & $1(0.3)$ \\
\hline CAVB & $1(0.3)$ \\
\hline \multicolumn{2}{|l|}{ Others } \\
\hline RV failure & $1(0.3)$ \\
\hline Misdiagnosis of PAPVR & $1(0.3)$ \\
\hline Surgical removal & $2(0.5)$ \\
\hline RV failure/misdiagnosis of PAPVR & $1 / 1$ \\
\hline $\begin{array}{l}\text { Discharge with ASD device (success of } \\
\text { procedure) }\end{array}$ & 397 \\
\hline Mid-term follow up & $(n=376)$ \\
\hline Follow-up duration (months) & $30.3(3.6-140.8)$ \\
\hline Complication & $5(1.3)$ \\
\hline Aggravation of MR & $5(1.3)$ \\
\hline Increase +1 /increase +2 & $5 / 0$ \\
\hline Device embolization & $0(0)$ \\
\hline PV, SVC, or IVC flow disturbance & $0(0)$ \\
\hline Aortic erosion & $0(0)$ \\
\hline LV dysfunction & $0(0)$ \\
\hline cAVB & $0(0)$ \\
\hline Arrhythmia & $0(0)$ \\
\hline ASD device leakage at discharge & $44 / 397(11.1)$ \\
\hline $\begin{array}{l}\text { ASD device leakage at first follow-up } \\
\text { echocardiography }\end{array}$ & $7 / 376(1.9)$ \\
\hline
\end{tabular}

LA, left atrial; LV, left ventricle; MR, mitral regurgitation; PAPVR, partial anomalous pulmonary venous return; RV, right ventricle. Other abbreviations as in Table 1.

tional methods (novel techniques) in 56 cases (pulmonary vein technique in 33 cases and balloon-assisted technique in 23 cases); thus, these cases were considered challenging cases. Two devices were deployed in 6 patients. The most commonly used device was the Amplatzer ${ }^{\circledR}$ Septal Occluder. A single Amplatzer ${ }^{\circledR}$ Septal Occluder was used in 280 patients (including 5 failed cases). Two Amplatzer ${ }^{\circledR}$ Septal Occluder devices were used in 4 patients, and the Amplatzer ${ }^{\circledR}$ Septal Occluder was used as a second device in 1 patient (followed Occlutech ${ }^{\circledR}$ Figulla Flex II). We analyzed these 280 patients with a single Amplatzer ${ }^{\circledR}$ Septal Occluder group in the logistic regression model.

In recent practice, we use the Occlutech ${ }^{\circledR}$ Figulla Flex II more.

\section{Peri-Procedure and Follow-up Outcomes}

Post-procedural acute complications during admission occurred in 5 patients $(1.3 \%)$ (Table 2). One 3-year-old patient $(0.3 \%)$ underwent device embolization within $24 \mathrm{~h}$ post-intervention. The percutaneous device removal and re-implantation of a larger device for this patient were successful. One case each of the left atrial disc touching the MV without MR aggravation, complete atrioventricular block, right ventricular failure, and misdiagnosis of partial anomalous pulmonary venous return occurred. Among these 5 post-procedural acute complications, surgical device removal was performed in 2 cases ( 1 right ventricular failure and 1 partial anomalous pulmonary venous return). No case of pulmonary or systemic vein flow disturbance and aortic erosion occurred. Among 399 patients with procedure completion, 397 (97.5\%) were discharged with appropriate placement of the ASD device (Table 3).

Among the 397 patients whose interventions were successful, 376 patients had follow-up data. The median followup duration was 30.3 (3.6-140.8 months). No new device embolization, pulmonary or systemic vein flow obstructions, aortic erosion, left ventricular dysfunction, complete atrioventricular block, or arrhythmia occurred during the follow up. Five patients (1.3\%) showed MR aggravation (all of them showed an increase of 1 grade of MR), and 4 of them did not have MV prolapse. At the time of discharge, $11.1 \%(44 / 397)$ of the patients had closure site leakage, whereas only $1.9 \%$ (7/376) had closure site leakage at the first follow-up echocardiography (Table 2).

\section{Logistic Regression Model for Procedural Failure and Challenging Cases}

The logistic regression analysis was performed for the single Amplatzer ${ }^{\circledR}$ Septal Occluder group. In the univariate logistic regression model for procedural failure, ASD size, measurements of the PI and PS rims, and combinations of SVC-PI and IVC-retroaortic rims deficiency were identified as candidate risk factors. However, in the multivariate analysis, only ASD size (odds ratio 1.828, 95\% CI 1.139-2.934; $\mathrm{P}=0.012$ ) was found to be associated with procedural failure (Table 3). Moreover, in the multivariate logistic regression model for challenging cases, only ASD size in millimeters (odds ratio 1.371, 95\% CI 1.180-1.593; $\mathrm{P}<0.001$ ) was found to be associated with using non-conventional methods (Table 4).

The ROC curve of the logistic regression model for procedural failure is shown in Figure A. The AUC for ASD size was 0.952 (95\% CI: 0.906-0.999, $\mathrm{P}=0.001)$. The ROC curve of challenging cases is shown in Figure B; the AUC of ASD size was 0.840 (95\% CI: 0.775-0.906, $\mathrm{P}<0.001)$. These findings suggest that the model including ASD size adequately predicted procedural failure and non-conventional methods.

\section{Discussion}

The major findings of the present study were as follows: (1) percutaneous ASD closure is feasible and safe in preschool children (median age of 3 years in this study), even in children with some rim deficiencies, and (2) large-sized ASD is the only predictor of procedural failure and challenging cases in young children.

Recently, large studies reported the feasibility and safety of percutaneous ASD closure in children and adolescents, ${ }^{14,19,20}$ however, the majority of patients in those studies were school-aged children and teenagers. The feasibility and safety of percutaneous ASD closure in children aged $<6$ years were unclear because they are physically smaller. Moreover, there was a concern of secundum ASD closing spontaneously in children of pre-school age. Therefore, these pre-school children were often followed up until they 


\begin{tabular}{|c|c|c|c|c|}
\hline & \multicolumn{2}{|l|}{ Univariate } & \multicolumn{2}{|l|}{ Multivariate } \\
\hline & OR $(95 \% \mathrm{Cl})$ & $P$ value & OR $(95 \% \mathrm{Cl})$ & $P$ value \\
\hline Sex (female) & $0.844(0.139-5.135)$ & 0.854 & - & - \\
\hline Age at closure (years) & $1.685(0.729-3.894)$ & 0.223 & - & - \\
\hline $\operatorname{BSA}\left(m^{2}\right)$ & $1,189.140(0.100-14108610)$ & 0.139 & - & - \\
\hline ASD size $(\mathrm{mm})$ & $1.622(1.212-2.172)$ & 0.001 & $1.828(1.139-2.934)$ & 0.012 \\
\hline Multiple ASDs & $0.000(0.000-)$ & 0.998 & - & - \\
\hline Used sizing balloon & $1.559(0.170-14.326)$ & 0.695 & - & - \\
\hline SVC rim (mm) & $1.045(0.830-1.315)$ & 0.711 & - & - \\
\hline IVC rim (mm) & $0.833(0.645-1.075)$ & 0.159 & - & - \\
\hline retroAo rim $(\mathrm{mm})$ & $1.113(0.783-1.582)$ & 0.549 & - & - \\
\hline PI rim (mm) & $0.644(0.413-1.004)$ & 0.052 & $1.218(0.579-2.564)$ & 0.604 \\
\hline MV rim (mm) & $1.047(0.740-1.480)$ & 0.796 & - & - \\
\hline PS rim (mm) & $0.603(0.396-0.917)$ & 0.018 & $0.816(0.439-1.514)$ & 0.519 \\
\hline retroAo-PI rims deficiency & $1.911(0.207-17.652)$ & 0.568 & - & - \\
\hline SVC-PS rims deficiency & $0.000(0.000-)$ & 0.999 & - & - \\
\hline PS-PI rims deficiency & $0.000(0.000-)$ & 0.999 & - & - \\
\hline SVC-PI rims deficiency & $13.350(1.257-141.836)$ & 0.032 & $8.676(0.252-298.360)$ & 0.231 \\
\hline IVC-retroAo rims deficiency & $13.200(1.242-140.247)$ & 0.032 & $12.074(0.227-641.334)$ & 0.219 \\
\hline Atrial septal malalignment & $0.000(0.000-)$ & 0.999 & - & - \\
\hline
\end{tabular}

ASO, Amplatzer Septal Occluder; $\mathrm{Cl}$, confidence interval; OR, odds ratio. Other abbreviations as in Table 1.

\begin{tabular}{|c|c|c|c|c|}
\hline & \multicolumn{2}{|l|}{ Univariate } & \multicolumn{2}{|l|}{ Multivariate } \\
\hline & OR $(95 \% \mathrm{Cl})$ & $P$ value & OR $(95 \% \mathrm{Cl})$ & $P$ value \\
\hline Sex (female) & $2.100(0.818-5.392)$ & 0.123 & - & - \\
\hline Age at closure (years) & $0.845(0.565-1.266)$ & 0.415 & - & - \\
\hline $\mathrm{BSA}\left(\mathrm{m}^{2}\right)$ & $0.024(0.000-2.764)$ & 0.124 & - & - \\
\hline ASD size $(\mathrm{mm})$ & $1.353(1.210-1.514)$ & $<0.001$ & $1.371(1.180-1.593)$ & $<0.001$ \\
\hline Multiple ASDs & $0.343(0.045-2.637)$ & 0.304 & - & - \\
\hline Used sizing balloon & $2.450(0.958-6.268)$ & 0.062 & $0.774(0.219-2.741)$ & 0.692 \\
\hline SVC rim (mm) & $0.848(0.749-0.961)$ & 0.010 & $0.938(0.800-1.100)$ & 0.431 \\
\hline IVC rim (mm) & $0.917(0.826-1.019)$ & 0.107 & - & - \\
\hline retroAo rim $(\mathrm{mm})$ & $1.017(0.849-1.218)$ & 0.854 & - & - \\
\hline $\mathrm{PI} \operatorname{rim}(\mathrm{mm})$ & $0.796(0.675-0.940)$ & 0.007 & $1.115(0.855-1.455)$ & 0.421 \\
\hline $\mathrm{MV} \operatorname{rim}(\mathrm{mm})$ & $0.967(0.820-1.140)$ & 0.686 & - & - \\
\hline PS rim (mm) & $0.734(0.621-0.867)$ & $<0.001$ & $0.902(0.719-1.133)$ & 0.377 \\
\hline retroAo-PI rims deficiency & $3.991(1.573-10.126)$ & 0.004 & $0.969(0.215-4.379)$ & 0.968 \\
\hline SVC-PS rims deficiency & $10.478(2.457-44.688)$ & 0.002 & $1.694(0.166-17.339)$ & 0.657 \\
\hline PS-PI rims deficiency & $2.925(0.753-11.361)$ & 0.121 & - & - \\
\hline SVC-PI rims deficiency & $15.187(2.418-95.408)$ & 0.004 & $7.558(0.360-158.558)$ & 0.193 \\
\hline IVC-retroAo rims deficiency & $2.288(0.246-21.248)$ & 0.467 & - & - \\
\hline Atrial septal malalignment & $0.000(0.000-)$ & 0.999 & - & - \\
\hline
\end{tabular}

Abbreviations as in Tables 1,3.

were old enough for device closure in many centers. ${ }^{\mathbf{2 1}}$ Even in the largest study of percutaneous ASD closure in children and adolescents, children aged $<6$ years made up only $17.0 \%$ (229 patients) of the study population. ${ }^{14}$ However, most spontaneous ASD closures occurred within the first year of life. ${ }^{22}$ Thus, the guidelines recommend an elective closure between 2 and 5 years of age in asymptomatic patients with a large left-to-right shunt. ${ }^{2}$ Moreover, this study with 407 confirmed cases of percutaneous ASD closure in children aged $<6$ years showed that percutaneous ASD closure in children aged $<6$ years was also feasible and safe like percutaneous closure in school-age or teenage children. We emphasized that this strategy is "return to recommendation (elective closure between 2 and 5 years of age)" and would result in a shorter exposure to volume overload of the right ventricle and atrium than in percutaneous ASD closure in older children. Thus, percutaneous closure has to be considered in preschool children with ASD and a con- 
A

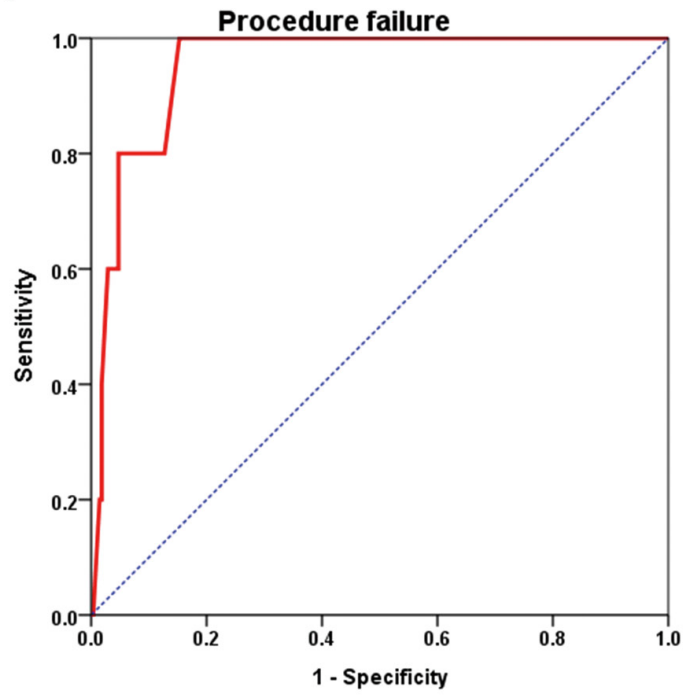

B

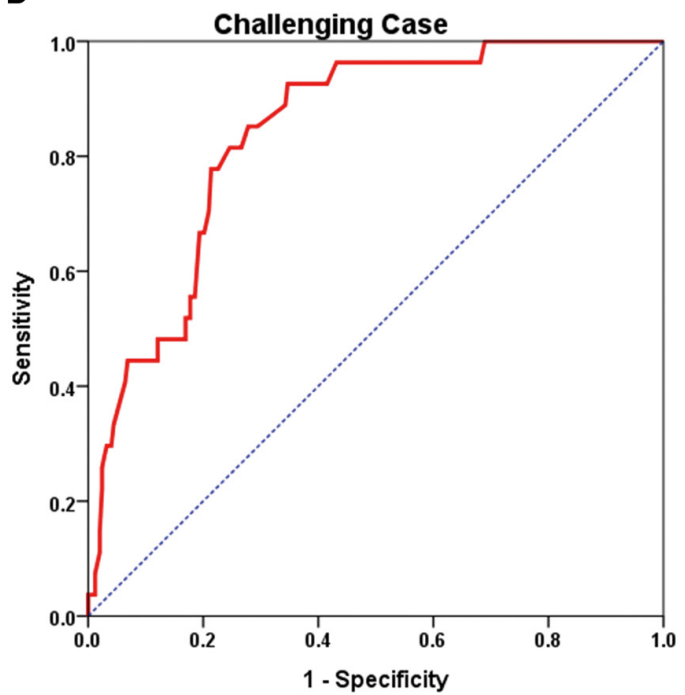

Figure. ROC curves (red lines) of ASD size for procedural failure $(\mathbf{A})$ and challenging case $(\mathbf{B})$. In the model for procedural failure, the AUC of the ASD size was $0.952(95 \% \mathrm{Cl} 0.906-0.999 ; \mathrm{P}=0.001)$. The AUC of the ASD size in the model that used non-conventional methods was 0.840 (95\% Cl 0.775-0.906; P<0.001). ASD, atrial septal defect; AUC, area under the curve; PS, posteriorsuperior; ROC, receiver operating characteristic; $\mathrm{Cl}$, confidence interval.

firmed large left-to-right shunt. In our center, we generally performed percutaneous ASD closure after 3 years old, which is the timing of elective surgical closure in the past.

To the best of our knowledge, this is the largest study of percutaneous ASD closure in children aged $<6$ years.

\section{Procedure Data}

In our center, we used the Occlutech ${ }^{\circledR}$ Figulla Flex II more than the Amplatzer ${ }^{\circledR}$ Septal Occluder. Until 2014, pediatric interventional cardiologists in our center could use only the Amplatzer ${ }^{\circledR}$ Septal Occluder, Amplatzer ${ }^{\circledR}$ PFO Occluder, or Amplatzer ${ }^{\circledR}$ Cribriform Septal Occluder in percutaneous ASD closure. After the Korean authorities approved the novel devices (2015), we used Occlutech ${ }^{\circledR}$ Figulla Flex II more frequently, because the pediatric interventional cardiologists in our center asserted that this novel device was softer and easier to deploy. Recent literature also reported the feasibility of ASD closure with the novel device, probably due to the tiltable delivery system, which enabled the rapid and ideal alignment with the septum. ${ }^{23}$

\section{Peri-Procedural and Follow-up Outcomes}

In this study, the procedural completion rate was $98.0 \%$, and only 2 patients required post-interventional surgical removal of the device. Thus, the overall successful closure rate at discharge was $97.5 \%$. This high success rate is comparable to that reported in previous studies. ${ }^{14,15,20,21,24}$

The incidences of peri-procedural and follow-up complications were only $1.3 \%$ each. In addition, only 3 cases of peri-procedural complications required further surgical or percutaneous intervention, and no major complications requiring additional intervention occurred after discharge during the follow up period.

Among the 4 cases of intra-procedural complications, percutaneous ASD closure failure due to MV compression by the LA disc was seen in 3 patients. One of the 3 patients had an anterior mitral leaflet prolapse with mild regurgitation, and the other 2 patients showed no MV prolapse with trivial regurgitation. All 3 patients had sufficient MV rims $(7.0,9.6$, and $10.7 \mathrm{~mm})$ and other rims, except for the retroaortic rim at the pre-procedural TTE. The ASD sizes in TEE were rather large $(19.4,25.0$, and $27.0 \mathrm{~mm})$ in these patients. For the deployment, a conventional method was used in 2 cases, and the balloon-assist technique was used in 1 case. After device deployment, the LA disc immediately compressed the mitral anterior leaflet and restricted motion, resulting in MR aggravation in all the 3 patients. We concluded that a sufficient MV rim did not always guarantee the proper deployment of the device in large defects. Thus, a post-deployment check for MV motion would be very important in large ASDs.

In the present study, 1 patient $(0.3 \%)$ experienced device embolization within $24 \mathrm{~h}$ after intervention, and no new cases of device embolism occurred after discharge. This obtained value was somewhat lower than that found in recent studies that reported a device migration rate of $0.8-1.0 \%$ during the peri-procedural period. ${ }^{\mathbf{1 4}, 19}$

In this study, 1 patient who was diagnosed with Alagille syndrome pre-procedurally, underwent surgical device removal for right ventricular failure. This patient had secundum ASD and a moderate pulmonary valvular and branch arterial stenosis. We performed percutaneous ASD closure and pulmonary balloon valvuloplasty and angioplasty, simultaneously. After ballooning, the trans-valvular pressure gradient was not significantly improved $(26 \rightarrow 28 \mathrm{mmHg})$, and the branch pulmonary stenosis was somewhat improved (left pressure gradient, $34 \rightarrow 17 \mathrm{mmHg}$; right pressure gradient, $28 \rightarrow 25 \mathrm{mmHg}$ ). The right ventricular systolic pressure decreased slightly from 82 to $80 \mathrm{mmHg}$. Post-procedural echocardiography showed a persistent high right ventricu- 
lar systolic pressure and right ventricular dysfunction; thus, we decided to perform a surgical right ventricular outflow relief, bilateral pulmonary angioplasty, and ASD closure after device removal. Since this case, we have not performed a percutaneous ASD closure in a patient with more than a moderate branch pulmonary stenosis, especially in patients with Alagille syndrome.

Aortic erosion is considered the most serious delayed complication and has been reported mainly when the Amplatzer ${ }^{\circledR}$ Septal Occluder is used. ${ }^{25}$ The estimated incidence is $0.04-0.23 \%{ }^{26}$ However, recent large scale studies in children, ${ }^{14,19}$ including the present study, reported no cases of aortic erosion in the mid- to long-term follow up, despite a considerable proportion of retro-aortic rim deficiency. The incidence of aortic erosion could be underestimated because some cases of erosion may resolve spontaneously, and the previous and present study had a proportion of patients who were lost to follow up. ${ }^{14} \mathrm{We}$ assume that aortic erosion may be an extremely rare complication in children; however, as a precaution, long-term follow up is required after the procedure.

In this study, a substantially lower number of patients $(1.0 \%)$ showed new-onset or aggravation of MR. We assumed that this aggravation of MR in a few patients was caused by closing the left-to-right shunt and the device itself (such as restriction of MV excursion by LA disc), and MV prolapse was less likely associated with these cases. The potential risk of new-onset or aggravation of MR after surgical ASD closure in adults is well described in the literature. ${ }^{27}$ One study from New Zealand reported that $9 \%$ of patients showed aggravation of MR after percutaneous ASD closure in a mixed group of children and adults. ${ }^{28}$ This phenomenon was probably caused by left ventricle decompensation, which is caused by increasing inflow after ASD closure. We observed that only $1.0 \%$ of patients had MR aggravation, and this number was much lower in the adult or mixed group (children and adults). We assumed that the risk of new-onset or aggravation of MR was much lower in young children than in adults; however, the risk was not zero. Thus, regular echocardiographic follow up is recommended.

\section{Logistic Regression Model for Procedural Failure and Challenging Cases}

In the multivariate logistic regression model of procedural failure, large-sized ASD was found to be the only predictor of failure, similar to the finding of a previous study on ASD closure in infants and toddlers. ${ }^{21}$ However, rim measurement was not associated with procedural failure in the present study. Some previous studies noted that deficient MV or IVC rims were crucial for device deployment. ${ }^{\mathbf{8 , 2 9}}$ Considering the anatomical criteria for transcatheter ASD closure in our center, selection bias may have resulted in this significant difference. Nevertheless, we asserted that any rims (except the MV rim) $<5 \mathrm{~mm}$ is not an absolute contraindication for percutaneous ASD closure in preschool aged children.

Regarding procedure completion, the conventional method accounted for $86.0 \%$ of the procedures; the remaining $14.0 \%$ of cases were closed by using non-conventional techniques. Given that the latter group comprised technically challenging cases, we attempted to analyze the predictors for using non-conventional methods to prepare for challenging cases prior to the procedure. In the multivariate logistic regression model, only large-sized ASDs were associated with challenging cases in preschool aged children.

\section{Study Limitations}

This study had some limitations because of its retrospective nature. The outpatient clinic visits and echocardiographic follow up were somewhat irregular. Some patients were lost to follow up, although the proportion was low. This could have caused the underestimation of the incidence of complications. We previously reported that larger-sized ASDs and a small-sized left atrium were predictors of using modified methods for deployment. ${ }^{16}$ However, in the present study, there was a lack of TTE images in the mid-to-late $2000 \mathrm{~s}$, and we could not analyze the relationship between left atrial size in TTE and challenging cases. We plan to analyze this relationship in future using more recent data.

In conclusion, percutaneous ASD closure in children aged $<6$ years is feasible and safe and should be considered in young children with ASD and confirmed large left-toright shunts. Large-sized ASDs was the only predictor for procedural failure and challenging cases. In young children, procedural complications were rare and minor; however, long-term follow up is required due to the possibility of delayed complications.

\section{Acknowledgments}

None.

\section{Sources of Funding}

No funding was received.

\section{Disclosures}

The authors declare that there are no conflicts of interest.

\section{IRB Information}

The present study was approved by the hospital's institutional review board (Asan Medical Center 2020-0339).

\section{Data Availability}

Data cannot be provided as per the IRB protocol.

\section{References}

1. Hoffman JIE, Kaplan S. The incidence of congenital heart disease J Am Coll Cardiol 2002; 39: 1890-1900.

2. Driscoll D, Allen HD, Atkins DL, Brenner J, Dunnigan A, Franklin $\mathrm{W}$, et al. Guidelines for evaluation and management of common congenital cardiac problems in infants, children, and adolescents: A statement for healthcare professionals from the Committee on Congenital Cardiac Defects of the Council on Cardiovascular Disease in the Young, American Heart Association. Circulation 1994; 90: 2180-2188.

3. King TD, Thompson SL, Steiner C, Mills NL. Secundum atrial septal defect. Nonoperative closure during cardiac catheterization. JAMA 1976; 235: 2506-2509.

4. Du ZD, Hijazi ZM, Kleinman CS, Silverman NH, Larntz K; Amplatzer Investigators. Comparison between transcatheter and surgical closure of secundum atrial septal defect in children and adults: Results of a multicenter nonrandomized trial. $\mathrm{J} \mathrm{Am} \mathrm{Coll}$ Cardiol 2002; 39: 1836-1844.

5. Karamlou T, Diggs BS, Ungerleider RM, McCrindle BW, Welke $\mathrm{KF}$. The rush to atrial septal defect closure: Is the introduction of percutaneous closure driving utilization? Ann Thorac Surg 2008; 86: $1584-1590$

6. Masura J, Gavora P, Formanek A, Hijazi ZM. Transcatheter closure of secundum atrial septal defects using the new self-centering amplatzer septal occluder: Initial human experience. Cathet Cardiovasc Diagn 1997; 42: 388-393.

7. Momenah TS, McElhinney DB, Brook MM, Moore P, Silverman $\mathrm{NH}$. Transesophageal echocardiographic predictors for successful transcatheter closure of defects within the oval fossa using the CardioSEAL septal occlusion device. Cardiol Young 2000; 10: $510-518$.

8. Mazic U, Gavora P, Masura J. The role of transesophageal echo- 
cardiography in transcatheter closure of secundum atrial septal defects by the Amplatzer septal occluder. Am Heart J 2001; 142: $482-488$.

9. Thanopoulos BD, Biasco L, Dardas P, De Backer O, Avraamides $\mathrm{P}$, Deleanou D, et al. Catheter closure of atrial septal defects using the Cocoon septal occluder: Preliminary results of a European multicenter study. Int J Cardiol 2014; 177: 418-422.

10. Kenny D, Eicken A, Dahnert I, Boudjemline Y, Sievert H, Schneider $\mathrm{MB}$, et al. A randomized, controlled, multi-center trial of the efficacy and safety of the Occlutech Figulla Flex-II Occluder compared to the Amplatzer Septal Occluder for transcatheter closure of secundum atrial septal defects. Catheter Cardiovasc Interv 2019; 93: $316-321$

11. Papa M, Gaspardone A, Fragasso G, Sidoti F, Agricola E, Gioffre $\mathrm{G}$, et al. Feasibility and safety of transcatheter closure of atrial septal defects with deficient posterior rim. Catheter Cardiovasc Interv 2013; 81: 1180-1187.

12. Dalvi BV, Pinto RJ, Gupta A. New technique for device closure of large atrial septal defects. Catheter Cardiovasc Interv 2005; 64: $102-107$.

13. Huang TC, Hsieh KS, Lin CC, Lee CL. Clinical results of percutaneous closure of large secundum atrial septal defects in children using the Amplatzer septal occluder. Heart Vessels 2008; 23: $187-192$.

14. Jalal Z, Hascoet S, Gronier C, Godart F, Mauri L, Dauphin C, et al. Long-term outcomes after percutaneous closure of ostium secundum atrial septal defect in the young: A nationwide cohort study. JACC Cardiovasc Interv 2018; 11: 795-804.

15. Cao C, Wang Z, Huang J, Fan L, Li R, Wang S, et al. Feasibility, safety and long-term follow-up of transcatheter closure of secundum atrial septal defects with deficient rims. Cardiology 2016; 134: $118-126$.

16. Ko HK, Kang SY, Yu JJ, Ko JK, Kim YH. Small left atrial size complicating percutaneous transcatheter device closure of secundum atrial septal defect with conventional approach. Korean Circ J 2015; 45: 216-224.

17. Cooke JC, Gelman JS, Harper RW. Echocardiologists' role in the deployment of the Amplatzer atrial septal occluder device in adults. J Am Soc Echocardiogr 2001; 14: 588-594.

18. Harper RW, Mottram PM, McGaw DJ. Closure of secundum atrial septal defects with the Amplatzer septal occluder device: Techniques and problems. Catheter Cardiovasc Interv 2002; 57: $508-524$
19. Baruteau AE, Hascoet S, Fraisse A. Transthoracic echocardiography is a safe alternative for assessment and guidance of transcatheter closure of secundum atrial septal defect in children. $J$ Thorac Dis 2017; 9: 1247-1256.

20. Saritas T, Yucel IK, Demir IH, Demir F, Erdem A, Celebi A Comparison of transcatheter atrial septal defect closure in children, adolescents and adults: Differences, challenges and short-, mid- and long-term results. Korean Circ J 2016; 46: 851 -861.

21. Petit CJ, Justino H, Pignatelli RH, Crystal MA, Payne WA, Ing FF. Percutaneous atrial septal defect closure in infants and toddlers: Predictors of success. Pediatr Cardiol 2013; 34: 220-225.

22. Radzik D, Davignon A, van Doesburg N, Fournier A, Marchand T, Ducharme G. Predictive factors for spontaneous closure of atrial septal defects diagnosed in the first 3 months of life. $J \mathrm{Am}$ Coll Cardiol 1993; 22: $851-853$.

23. Haas NA, Soetemann DB, Ates I, Baspinar O, Ditkivskyy I, Duke C, et al. Closure of secundum atrial septal defects by using the occlutech occluder devices in more than 1300 patients: The IRFACODE Project: A Retrospective Case Series. Catheter Cardiovasc Interv 2016; 88: 571-581.

24. Bartakian S, Fagan TE, Schaffer MS, Darst JR. Device closure of secundum atrial septal defects in children $<15 \mathrm{~kg}$ : Complication rates and indications for referral. JACC Cardiovasc Interv 2012; 5: $1178-1184$

25. Jalal Z, Hascoet $S$, Baruteau AE, Iriart X, Kreitmann B, Boudjemline $\mathrm{Y}$, et al. Long-term complications after transcatheter atrial septal defect closure: A review of the medical literature. Can J Cardiol 2016; 32: 1315.e11-1315.e18.

26. Diab K, Kenny D, Hijazi ZM. Erosions, erosions, and erosions! Device closure of atrial septal defects: How safe is safe? Catheter Cardiovasc Interv 2012; 80: 168-174.

27. Park JJ, Lee SC, Kim JB, Seo DJ, Song JM, Yun SC, et al. Deterioration of mitral valve competence after the repair of atrial septal defect in adults. Ann Thorac Surg 2011; 92: 1629-1633.

28. Wilson NJ, Smith J, Prommete B, O'Donnell C, Gentles TL, Ruygrok PN. Transcatheter closure of secundum atrial septal defects with the Amplatzer septal occluder in adults and children-follow-up closure rates, degree of mitral regurgitation and evolution of arrhythmias. Heart Lung Circ 2008; 17: 318-324.

29. Ostermayer SH, Srivastava S, Doucette JT, Ko HH, Geiger M, Parness IA, et al. Malattached septum primum and deficient septal rim predict unsuccessful transcatheter closure of atrial communications. Catheter Cardiovasc Interv 2015; 86: 1195-1203. 